\title{
Um diploma em disputa: a obrigatoriedade do diploma em jornalismo no Brasil
}

\author{
Lerisson C. Nascimento \\ Doutorando em Sociologia (Universidade Federal de São Carlos) \\ Bolsista da CAPES. \\ lerisson@gmail.com
}

\begin{abstract}
Resumo A proposta deste artigo é demonstrar como a profissão de jornalista no Brasil foi objeto de disputas nos últimos anos no judiciário brasileiro, especialmente no Supremo Tribunal Federal (STF). Mostramos que a disputa ocorreu em torno da obrigatoriedade do diploma em jornalismo para o exercício legal da profissão. Para a Constituição brasileira de 1988, algumas ocupações possuem uma reserva legal qualificada, o que significa que elas exigem um diploma universitário para o exercício da profissão. O STF considerou o jornalismo uma ocupação na qual liberdade de expressão e liberdade de profissão têm a mesma natureza. Baseado na ideia de que num país democrático não deve haver regulamentação prévia da liberdade de expressão, o STF decidiu que não deve existir nenhum tipo de regulamentação estatal na profissão de jornalista.
\end{abstract}

Palavras-chave: profissão; jornalismo; Supremo Tribunal (STF); expertise.

$\mathrm{O}$ DEBATE RELACIONADO À anÁlise sociológica de grupos profissionais e/ou comportamentos profissionais no mundo do trabalho se vê às voltas com a temática do credencialismo. Quais critérios são utilizados por grupos ocupacionais que procuram delimitar suas fronteiras, sejam elas institucionais ou identitárias, em relação a outras ocupações no mercado de trabalho? Diniz (2001) mostra que, a despeito da diversidade do fenômeno da organização profissional em diferentes contextos históricos e nacionais, um item é comum: o requisito da educação formal de Nível Superior. Para além deste, outros critérios são exigidos conforme o grupo e os diferentes contextos, porém esta é a base sobre a qual se assenta a diferença desta forma de organização do trabalho das demais.

Como mostra Coelho (1999), especialmente para o contexto brasileiro, existem estruturas jurídicas distintas quando se trata da regulamentação, por parte do Estado, das relações de traba1ho. Uma estrutura se dedica às ditas profissões e outra, às demais ocupações. Há decretos e leis dedicados especialmente à regulamentação dessas atividades consideradas importantes para o "bem comum" da sociedade.

O artigo $5^{\circ}$ da Constituição de 1988 garante a igualdade de todos perante a lei, brasileiros ou estrangeiros residentes no Brasil, sem distinção. Assegura a inviolabilidade do direito à vida, à liberdade, à segurança e à propriedade. São elencados 78 incisos que versam sobre as especificidades dessas garantias, um deles em especial é importante para 
nossa discussão, o inciso XIII. Este inciso assevera que "é livre o exercício de qualquer trabalho, ofício ou profissão, atendidas as qualificações profissionais que a lei estabelecer".

O trecho "atendidas as qualificações profissionais que a lei estabelecer" abre espaço para disputas - que tomam o espaço político-jurídico como campo de batalha - na medida em que tais qualificações são fruto de legislação ordinária, tendo o Congresso Nacional papel central nesse processo. Dadas as características do sistema de regulamentação de relações de trabalho no Brasil - que possui algumas leis regulamentares ainda em vigor criadas no período pré-1988, durante o regime militar, há disputas no judiciário acerca da legitimidade de tais regulamentações, esse era o caso da ocupação de jornalista.

Nossa proposta neste artigo é mostrar como o jornalismo - como ocupação no mercado de trabalho - foi objeto de disputas judiciais nos últimos dez anos, culminando com a decisão tomada pelo Supremo Tribunal Federal (STF) em 2009 que institui a não obrigatoriedade do diploma universitário em jornalismo para o exercício da profissão. Concebemos aqui as disputas em torno do jornalismo no Brasil desde o século XIX - a despeito do espaço onde ocorrem, se no mercado de trabalho ou nos espaços institucionalizados da política e do judiciário - como embates acerca de um tipo de saber jornalístico e de quem tem a legitimidade para aplicá-lo no trabalho.

Mostramos como as decisões - uma a favor e duas contra a obrigatoriedade do diploma - se relacionam a visões de mundo que embasam o uso da expertise no mercado de trabalho. As decisões judiciais refletem a forma através da qual se apresenta a politização da $e x$ pertise. No jornalismo, especificamente, a profissão é relacionada à liberdade de expressão, imperando, portanto, o princípio constitucional de não interferência do Estado no setor. Alguma interferência seria caracterizada como censura e crime contra a liberdade de expressão no país.

Johnson (1995), fazendo uso da noção de governamentalidade desenvolvida por Foucault, procura mostrar como a forma de organização do trabalho profissional surge entre os séculos XVIII e XIX como saber institucionalizado a serviço do Estado. As profissões surgem no bojo do desenvolvimento do Estado moderno, como tecnologias e saberes institucionalizados - e a partir da autoridade social inerente ao profissionalismo -, e tornam as complexidades sociais, econômicas e psicológicas da vida moderna cognoscíveis e passíveis de serem governadas. Dessa maneira, a relação entre Estado e profissões é compreendida não a partir de escalas que procuram medir uma maior ou menor influência do Estado nos grupos profissionais, mas sim na forma como o Estado participa da moldagem de grupos profissionais e como estes também moldam o Estado. Nesse sentido, a análise das decisões judiciais sobre a profissão de jornalista no Brasil nos mostra como essas esferas estão moldando uma a outra num processo de institucionalização de saberes.

Procuramos trabalhar apoiados na perspectiva de Foucault (2002), que em $A$ verdade e as formas jurídicas mostra que dentre as práticas sociais que engendram novas formas de saber, as práticas jurídicas estão entre as mais importantes. Estas são práticas regulares, formam um espaço em que as regras do jogo são definidas, onde um tipo de verdade se forma, são espaços de disputa. Em termos metodológicos, propõe a análise de discurso não no nível da formalidade, da estrutura da linguagem, e sim tomando os enunciados como jogo estratégico, de dominação e de luta. Partimos desse enquadramento em nossa proposta de análise sobre como o saber jornalístico - e consequentemente sua regulamentação profissional foi objeto de disputas no judiciário brasileiro.

Analisamos as seguintes decisões tomadas: em 2001, pela juíza Carla Abrantkoski Rister da $16^{a}$ Vara Civil de São Paulo, que considerou não obrigatório o diploma; em 2005, pelo juiz federal do Tribunal Regional Federal - $3^{a}$ Região que tomou decisão contrária a da juíza Rister; e o Recurso Extraordinário 511.961, do STF, de 2009, que teve como relator o ministro Gilmar Mendes, cuja decisão foi contra a obrigatoriedade do diploma.

O papel dos atores envolvidos nesse processo é de extrema importância, mas neste artigo estamos focando apenas as decisões tomadas pelos juízes e pelo STF. Os principais atores institucionais envolvidos no processo são o Ministério Público Federal e o Sindicato das Empresas de Rádio e Televisão no Estado de São Paulo como autores da Ação Civil Pública - e, como réus, a União Federal, a Federação Nacional dos Jornalistas e o Sindicato dos Jornalistas Profissionais do Estado de São Paulo. Essa configuração mostra a polarização entre capital e trabalho, entre empresas e associações dedicadas à defesa e promoção de direitos do trabalhador. Tais direitos de trabalho estão associados a direitos sociais mais amplos, como o direito à liberdade de informação.

\section{II}

A profissão de jornalista no Brasil esteve historicamente associada ao mundo da política e das artes em geral, em particular a literatura. Candiani (2009) situa o surgimento da imprensa nacional no século XIX com a vinda da Família Real para o país, mostrando como nesse período jornalistas e intelectuais exerciam o mesmo papel social. Essa configuração, no entanto, transformou-se no decorrer do século XX com a distinção e consolidação dos campos intelectual e jornalístico no país, no sentido dado por Bourdieu a esse processo. Para a autora, há uma relação ambígua entre jornalistas e intelectuais, existindo uma codependência entre esses atores sociais. 
O campo jornalístico se distinguiu historicamente do campo intelectual pelo desenvolvimento de duas características complementares: uma política, que diz respeito ao uso do discurso da objetividade e isenção em relação aos temas tratados (os fatos), ao contrário do campo intelectual que os trataria de maneira 'engajada'; e outra que corresponde ao uso do discurso da expertise, da técnica, a produção de conteúdo (textos, áudio, imagens) informativo produzido sob determinadas técnicas - como o lead ${ }^{1}$, por exemplo - contrapondo-se, assim, ao estilo ensaístico característico dos intelectuais brasileiros.

A prática jornalística constituiria em reunir mediante técnicas específicas como a reportagem, por exemplo - o máximo de informações factuais sobre determinado acontecimento e divulgá-las por meio de determinadas técnicas de apresentação. O jornalismo é conceituado assim como um conjunto de saberes e técnicas específicas, a técnica jornalística serve como base cognitiva, como capital que legitima a autonomia do campo.

Um pouco de história pode nos ajudar a entender tal compreensão sobre o processo de construção - ou de discursos - da especificidade técnica do jornalismo. Falando especificamente do desenvolvimento da imprensa carioca nos anos 1950, sendo o Rio de Janeiro ainda capital do país, Barbosa (2007) mostra que as ideias de desenvolvimentismo e modernização se tornaram mantras nas redações dos jornais diários. Esse período é retratado como palco de uma série de mudanças técnicas e organizacionais que afetaram o trabalho dos jornalistas, nele emerge e se consolida o discurso da objetividade no jornalismo brasileiro.

O Pompeu trouxe pra cá o que se fazia nos Estados Unidos - o copy ${ }^{2}$ - desk. Começava a nova imprensa. Primeiro, foi só o Diário Carioca; pouco depois, os outros, por imitação, o acompanharam. Rapidamente, os nossos jornais foram atacados de uma doença grave: - a objetividade. Daí para o idiota da objetividade seria um passo. [...] Eis o que eu queria dizer: -o idiota da objetividade inunda as mesas de redação e seu autor foi, mais uma vez, Pompeu de Souza. Aliás, devo dizer que o copy-desk e o idiota da objetividade são gêmeos e um explica o outro. (Rodrigues apud Barbosa, 2007, p. 150)
Para Nelson Rodrigues, as mudanças que vinham ocorrendo na imprensa procuravam transformar a notícia em um produto envolto numa aura de neutralidade e objetividade. Para tanto, segundo Barbosa (2007), faziam uso de técnicas que diminuíam o espaço de ação autoral dos jornalistas, daí a critica ácida de Nelson Rodrigues. Com essas mudanças, o jornalismo - ou o discurso sobre ele - procurava construir uma identidade própria que se diferenciava da literária, num processo de busca por autonomia do campo. As ideias de objetividade e neutralidade, operacionalizadas por meio das novas técnicas de redação e reportagem, davam ao jornalismo a legitimidade para ser a única esfera que poderia decifrar o mundo para o leitor. Os jornais ganham então a autoridade do discurso factual em contraposição ao retórico - este ligado ao mundo da literatura e da política -, mesmo mantendo sua carga opinativa.

Durante o regime militar, entre as décadas de 1960 e 1980, houve alto investimento do Estado no sistema de mídia brasileiro, o que contribuiu para a modernização tecnológica e organizacional. Se a relação do jornalismo com a literatura diminui - a partir de um processo de diferenciação no qual o papel da técnica é preponderante -, a relação aumenta com o mercado e com o Estado, torna-se cada vez mais complexa.

As disputas judiciais em torno da obrigatoriedade do diploma em jornalismo para exercer a profissão legalmente no mercado de trabalho brasileiro refletem em parte essa complexa relação da profissão com o Estado e com o mercado. Há instituições envolvidas no processo de desmonte da estrutura legal que garantia a obrigatoriedade do diploma em jornalismo no Brasil e assim colocam em xeque sua especificidade como categoria ocupacional detentora de expertise específica e importante para o 'bem comum' a ponto de ser necessária regulamentação por parte do Estado, configurando uma Reserva Legal Qualificada, tal como ocorre com as áreas de Medicina e Direito.

Se historicamente percebemos o desenvolvimento de conhecimentos específicos ou de discursos de especificidades técnicas, de saberes e tecnologias necessários ao funcionamento da esfera pública, como estes foram institucionalizados no espaço nacional brasileiro?

No Brasil, a primeira regulamentação do jornalismo como profissão surge em 1938 na Era Vargas ${ }^{3}$.

10 lead é o "relato sintético do acontecimento logo no começo do texto, respondendo às perguntas básicas do leitor: o quê, quem, como, onde, quando e por quê" (Pena, 2005, p. 41).

2 Copydesk é uma revisão feita no texto que leva em consideração, além dos aspectos ortográfico e gramatical, as características estilísticas, levando a um processo de padronização dos textos.

3 Essas disputas judiciais em torno da obrigatoriedade do diploma em jornalismo são fruto do desenvolvimento de um tipo de regulamentação das profissões existente no Brasil iniciada no Governo Vargas durante os anos 1930. A regulamentação tinha como objetivo a formalização da esfera produtiva como condição para implementação de políticas sociais compensatórias ou preventivas. A ideia de cidadania passou a ser relacionada com a regulamentação ocupacional, os direitos dos cidadãos estavam associados com sua inserção numa categoria ocupacional reconhecida legalmente pelo Estado (Coelho, 1999) e não com a ideia liberal de indivíduo que possui direitos individuais e inalienáveis. 
O primeiro decreto sobre a regulamentação da profissão já refletia o papel político dado pelo Estado a essa ocupação. O caput do Decreto-Lei n. 910, de 30 de novembro de 1938, que dispõe sobre a duração e as condições de trabalho em empresas jornalísticas, versa que "esses trabalhadores intelectuais são merecedores de amparo do Estado, tanto quanto mais quando este deve à Imprensa valiosa colaboração na obra de progresso nacional e no engrandecimento do Brasil".

Este Decreto estabelece a criação, por parte do governo federal, em acordo com os governos estaduais, de escolas de preparação destinadas aos profissionais da Imprensa, e, uma vez criadas tais escolas, a inscrição no Registro da Profissão Jornalística somente seria aceita para os novos profissionais mediante apresentação de diploma do curso ou de exames prestados nessas escolas. Inicia-se no Brasil um sistema de credenciamento federal dando origem à relação entre a criação e administração de saberes jornalísticos - dado o contexto histórico ligados à construção da nação (Pécault, 1990) - e a regulamentação destes em seu uso no espaço de trabalho, é formalizada uma diferenciação entre especialistas e leigos.

O Decreto-Lei n. 910, de 30 de novembro de 1938, foi o primeiro de uma série de decretos e leis que procuram regulamentar a profissão de jornalista no Brasil. O Decreto-Lei n. 5.480, de 13 de maio de 1943, instituiu o curso de Jornalismo no sistema de Ensino Superior do país; o Decreto-Lei n. 7.037, de novembro de 1944, dispõe sobre a remuneração mínima dos jornalistas; o Decreto-Lei n. 5.250, de 9 de fevereiro de 1967 (Lei de Imprensa), dispõe sobre a liberdade de informação e de pensamento; o Decreto-Lei n.1.177, de 12 de junho de 1962, aprova o regulamento sobre o registro de jornalista profissional; o Decreto n. 53.263, de 13 de dezembro de 1963, também dispõe acerca da aprovação do regulamento sobre o registro profissional, e finalmente o Decreto-Lei n. 972, de 17 de outubro de 1969, que dispõe sobre o exercício da profissão de jornalista, feito em período de exceção na vigência do Ato Institucional n. 5 de 13 de dezembro de 1968, decretado pelos Ministros de Guerra, do Exército e da Aeronáutica Militar. É sobre esse último Decreto-Lei que ocorrem as disputas judiciais acerca da regulamentação da profissão de jornalista no Brasil nos anos 2000. As disputas discursivas observadas nas decisões dos juízes e dos ministros do STF giram em torno da controvérsia acerca da legitimidade - em um regime político democrático - de um decreto criado em regime de exceção política.
A profissão de jornalista no Brasil chega ao século XXI professando o discurso da técnica, competência, objetividade e cidadania, características ligadas ao discurso do profissionalismo. Compreendemos profissionalismo aqui como um fenômeno social ligado ao domínio de uma expertise - assim como o desenvolvimento de uma ética e de um ethos profissional - e as formas por meio das quais os indivíduos possuidores desses conhecimentos especializados procuram criar, com base em suas redes de relações, mecanismos que possibilitem o monopólio da prática profissional (Freidson, 2001). Dessa maneira, a dimensão do processo de profissionalização, e assim as disputas em torno dele, ganham relevo ${ }^{4}$. Essa forma de interpretação nos ajuda a compreender a construção e legitimação de saberes dentro e fora do sistema acadêmico, o surgimento de identidades ocupacionais, assim como as relações entre grupos profissionais e os aparatos estatais e as estruturas de mercado ${ }^{5}$.

Esse enquadramento mostra a situação complexa na qual se encontra a ocupação de jornalista no Brasil, não podendo ser pensada apenas em uma dimensão. Procuramos contribuir com o debate sobre o jornalismo no Brasil mostrando como este tem sido objeto de disputas que envolvem aspectos legais, cognitivos e identitários no espaço jurídico, mudando o foco das diversas análises sobre o jornalismo no Brasil ${ }^{6}$ que estão centradas no exercício da profissão, seja abordando-a em si mesma com foco nas condições de trabalho ou a analisando como um espaço de produção de sentidos influenciado e influenciando, com mais ou menos intensidade, outros espaços, como o da política, economia e cultura.

\section{III}

As três decisões judiciais analisadas giram em torno de uma problemática ligada à constitucionalidade, ou seja, a recepção do artigo $4^{\circ}$, inciso V, do Decreto-Lei n. 972/1969 - que exigia o diploma de curso superior de jornalismo, registrado pelo Ministério da Educação para o exercício da profissão de jornalista pela Constituição Federal de 1988.

O artigo $4^{\circ}$ do Decreto-Lei 972/1969 reza que o

Exercício da profissão de jornalista requer prévio registro no órgão regional competente do Ministério do Trabalho e Previdência Social que se fará mediante

4 Evetts (2006) e Rodrigues (2002) mostram outras interpretações sobre o profissionalismo e os processos de profissionalização. As interpretações desenvolvidas nessa área específica - Sociologia das Profissões - vão desde aquelas pautadas no funcionalismo, até as mais recentes influenciadas pelos estudos culturais.

5 Para Freidson (1996), a noção de profissão ajuda a operacionalizar conceitos como discurso, no sentido dado por Foucault, e campo, na acepção de Bourdieu, pois ela proporciona a delimitação dos espaços de conflito de maneira mais clara. 
apresentação de: I - prova de nacionalidade brasileira; II - folha corrida; III carteira profissional; IV - declaração de cumprimento de estágio em empresa jornalística (Revogado pela Lei n. 6.612 de 7/1201978); V - diploma de curso superior de Jornalismo, oficial ou reconhecido, registrado no Ministério da Educação e Cultura ou em instituição por este credenciada, para as funções relacionadas de 'a' a 'g', no artigo $6^{\circ}$. (Neves, 2000, p. 131)

As funções de 'a' a 'g' do artigo $6^{\circ}$ - que versa sobre as funções dos jornalistas trabalhando como empregados - referem-se a redator, noticiarista, repórter, repórter de setor, rádiorrepórter, arquivista-pesquisador e revisor. $\mathrm{O}$ artigo $6^{\circ}$ ainda relaciona as funções de ilustrador, repórter-fotográfico, repórter-cinematográfico e diagramador como funções de jornalista, mas não necessariamente é obrigatório diploma em jornalismo para exercer essas funções.

Cada função está associada a um tipo de técnica específica, configurando uma espécie de divisão do trabalho jornalístico. O redator tem a função de fazer a redação comum, bem como escrever editoriais, crônicas e comentários; o noticiarista tem o papel de produzir matérias de caráter informativo sem nenhuma carga opinativa; o repórter a função de colher notícias e informações e prepará-las para divulgação; o repórter de setor teria a mesma função que um repórter, mas trabalhando em assuntos predeterminados; o radiorrepórter seria o profissional do rádio e da televisão, teria a função de transmitir oralmente os acontecimentos ou fazer entrevistas, comentários e crônicas através desses veículos; o arquivista-pesquisador organizaria e conservaria o arquivo redatorial e seria também o encarregado de pesquisas no mesmo para preparação de matérias; e o revisor faria a revisão das provas tipográficas das matérias. Também eram exclusivas dos jornalistas profissionais atividades como secretário, subsecretário, chefe de reportagem, chefe de revisão e editor (Neves, 2000, p. 131-132).

Essa era a compreensão institucionalizada acerca do trabalho jornalístico no Brasil no fim dos anos 1960. O não cumprimento dessas determinações por parte dos jornalistas e empresas resultaria em processos administrativos e criminais. O artigo 47 da Lei n. 3.688, de 3 de outubro de 1941, prevê prisão e multa para o exercício ilegal de profissão. Os sindicatos teriam a obrigação de comunicar as autoridades competentes o não cumprimento da Lei. As decisões judiciais que analisamos estavam às voltas com essa estrutura institucionalizada que regulamentava a profissão de jornalista no país.
O Ministério Público ajuizou Ação Civil Pública, julgada pela juíza Carla Rister em 2001, contra a obrigatoriedade do cumprimento do artigo $4^{\circ}$, inciso V, do Decreto-Lei n. 972/1969, baseado no art. 5º incisos IX e XIII, e art. 220, caput e parágrafo primeiro da CF/1988. O art. 5 da CF/1988 versa que "Todos são iguais perante a lei, sem distinção de qualquer natureza, garantindo-se aos brasileiros e aos estrangeiros residentes no País a inviolabilidade do direito à vida, à liberdade, à igualdade, à segurança e à propriedade". O inciso IX garante "a livre expressão da atividade intelectual, artística, científica e de comunicação, independentemente de censura ou licença”. E o inciso XIII reza que "é livre o exercício de qualquer trabalho, ofício ou profissão, atendidas as qualificações profissionais que a lei estabelecer".

$\mathrm{O}$ art. 220 assevera que "A manifestação do pensamento, a criação, a expressão e a informação, sob qualquer forma, processo ou veículo não sofrerão qualquer restrição, observado o disposto nesta Constituição”. O parágrafo primeiro reza que "Nenhuma lei conterá dispositivo que possa constituir embaraço à plena liberdade de informação jornalística em qualquer veículo de comunicação social, observado o disposto no art. $5^{\circ}$, IV, V, X, XIII e XIV”. O inciso IV do art. $5^{\circ}$ garante a livre manifestação do pensamento, sendo vedado o anonimato; o inciso $\mathrm{V}$ assegura o direito de resposta proporcional ao agravo e estipula indenização por dano material, moral ou à imagem; o inciso $X$ versa que "são invioláveis a intimidade, a vida privada, a honra e a imagem das pessoas, assegurado o direito a indenização pelo dano material ou moral decorrente de sua violação" e o inciso XIV, que assegura a todos o acesso à informação e garante o sigilo de fonte "quando necessário ao exercício profissional"”.

Os elementos discursivos usados pelo Ministério Público colocam ênfase no caráter não restritivo da CF/1988 em relação às liberdades de expressão e profissão, sendo o jornalismo uma ocupação na qual tais liberdades não deveriam conhecer qualquer obstáculo prévio. A seguir, passaremos à análise das decisões da juíza Carla Rister e do juiz Manuel Álvares e, em seguida, trataremos da decisão tomada pelo STF.

A decisão da juíza Carla Rister que derrubou a obrigatoriedade de diploma de Ensino Superior em Jornalismo para o exercício da profissão no país em 2001 acolhe a argumentação do Ministério Público. Segundo a sentença ${ }^{8}$, a obrigatoriedade infringia a liberdade de profissão (art. 5, inciso XIII, da CF/1988), além de não pressupor condições de capacidade para executar as atividades e assim infringir a liberdade de expressão, um bem comum importante à sociedade. 
A decisão contra a obrigatoriedade é tomada com base na noção de direito difuso ${ }^{9}$, ou seja, não seria um problema meramente individual, teria cunho social. Para a juíza, a interpretação da liberdade de exercício de trabalho deve ser associada a outras liberdades individuais; o artigo $4^{\circ}$, inciso $\mathrm{V}$, do Decreto-Lei $\mathrm{n}$. 972/1969 seria inconstitucional.

Interessante notar o debate presente na sentença sobre liberdade de profissão. A limitação a essa liberdade está associada a problemas com a 'defesa social', isto é, uma legislação específica para determinado tipo de exercício profissional seria necessária somente quando a técnica exigida pudesse prejudicar o direito de terceiros. $\mathrm{Na}$ interpretação da juíza, a preocupação vai além das questões técnicas envolvidas, as capacidades moral e física também seriam elementos a serem considerados na regulamentação de atividades profissionais.

A decisão também demonstra preocupação com o corporativismo, pois, na visão de Carla Rister, a obrigatoriedade favoreceria interesses corporativos de instituições responsáveis pela emissão das credenciais. A exigência do diploma também teria cunho elitista e contribuiria para o aumento das desigualdades sociais no país na medida em que prejudicaria a capacidade do pleno emprego da economia brasileira.

Vê-se que o valor protegido (pela obrigatoriedade do diploma) não é a fidelidade à verdade, nem os dotes de observador, intérprete ou comunicador do profissional, dado que as virtudes e qualidades que levam a bom desempenho, quanto a isso, não se aprendem em bancos acadêmicos. O que transparece protegido por essa interpretação é o 'valor' [?] corporativo, ao lado do prestígio compulsório dos estabelecimentos que, bem (o que é raro) ou mal (o que é mais comum), têm o privilégio de expedir tais diplomas. (Rister, 2001, fl. 28).

Para a juíza, o jornalismo deve ser exercido por pessoas com uma formação cultural sólida, característica que não seria exclusiva daqueles que possuem diplomas de jornalismo ou de outros cursos superiores. $\mathrm{O}$ jornalismo deveria ser praticado por

pessoas argutas, inteligentes, cultas e dotadas de qualidades comunicativas (escrita, fala, boa expressão), com a condição de que (ao transmitirem notícia sobre fatos e fenômenos objeto de conhecimento específico de profissões regulamentadas) sua interpretação e explicação provirão de profissionais formalmente qualificados (diplomados), a que deverão reportar-se os jornalistas (Rister, 2001, fl. 30)
O jornalista seria aquele que sabe perguntar e comunicar as respostas dadas por especialistas, pessoas inteligentes dotadas de capacidades comunicativas. Percebemos nesse trecho da sentença a manutenção do status daqueles grupos profissionais que dominam uma expertise, o que não seria o caso do jornalismo. Os especialistas, profissionais, informam à sociedade via jornalismo, a lógica da ocupação de jornalista; seu comportamento perante seu trabalho deveria ser a de todo e qualquer cidadão, ou seja, não haveria uma deontologia específica da profissão que legitimasse perante o Estado uma regulamentação especial, diferente das demais ocupações. $\mathrm{O}$ aprendizado pela prática atenderia bem às peculiaridades da profissão.

A ideia de uma base cognitiva específica, uma expertise e um comportamento moral na sua aplicação no mercado de trabalho é dissolvida pelo argumento da liberdade de exercício profissional e liberdade de expressão. A obrigatoriedade de diploma incentivaria $o$ corporativismo no mundo do trabalho e prejudicaria a livre circulação da informação no país. No entanto, o registro no Ministério do Trabalho não é considerado cerceamento ao exercício da atividade, este possibilita o acesso a uma série de direitos sociais aos trabalhadores, mas não diferencia seu status em relação a outras ocupações.

O juiz federal Manuel Álvares, do Tribunal Regional Federal $-3^{a}$ Região, em outubro de 2005, toma decisão contrária. Para este juiz, a CF/1988 contempla o artigo $4^{\circ}$ do Decreto-Lei n. 972/1969, e ele seria constitucional. O juiz se coloca contrário ao argumento usado pela juíza Carla Rister, listando as atividades que seriam específicas à profissão e que necessitariam de formação específica e regulamentação de tipo profissional. Para ele, não haveria confronto, no caso em análise, entre liberdade de profissão e liberdade de expressão.

Liberdade de comunicação não se confunde com a liberdade de profissão. Aquela é garantida a todos, protegida contra qualquer censura; esta é livre, atendidas as qualificações profissionais que a lei estabelecer. [...] Vale dizer que tal exigência [do diploma de jornalismo] não restringe o direito à comunicação, assegurado a todos, apenas exige determinada qualificação para o exercício da profissão de jornalista. Do contrário, a pretexto de usar da liberdade de comunicação, ou expressão, qualquer pessoa poderia requerer qualificação de jornalista, o que seria um absurdo ainda maior. (Álvares, 2005, p. 116)

9 "tem-se por direitos difusos [...] aqueles transindividuais (metaindividuais, supraindividuais, pertencentes a vários indivíduos), de natureza indivisível (só podem ser considerados como um todo), e cujos titulares sejam pessoas indeterminadas (ou seja, indeterminabilidade dos sujeitos, não há individuação) ligadas por circunstâncias de fato, não existe um vínculo comum de natureza jurídica, v.g., a publicidade enganosa ou abusiva, veiculada através de imprensa falada, escrita ou televisionada, a afetar uma multidão incalculável de pessoas, sem que entre elas exista uma relação jurídica-base" (Zanetti Júnior, 2005). 
Um dos argumentos apresentados nas duas decisões diz respeito à atividade de profissionais dentro do jornalismo, mas que não tem formação específica em jornalismo, eles se referem à figura do 'colaborador'. Para o juiz Manoel Álvarez, a atividade de colaborador era contemplada pela regulamentação já existente. O colaborador não seria um jornalista, mas alguém a quem seria dado espaço nas publicações, em geral um especialista em algum tema, não sendo tal situação contraditória com a exigência do diploma para exercício profissional. Na sentença, a profissão de jornalista é classificada como de cunho liberal e, para o juiz, deveria ter institucionalmente as características de uma profissão liberal.

Como é sabido, a profissão de jornalista é uma profissão liberal, assim entendida a que exige, por excelência, a intervenção do intelecto e para cujo exercício é indispensável o diploma do curso superior específico conferido por estabelecimento de ensino autorizado ou reconhecido. (Álvares, 2005, p. 122).

Nas sentenças analisadas, dois conflitos complementares são centrais: um que diz respeito ao status corporativo ou liberal na exigência do diploma como credencial; outro que se refere à especificidade da base cognitiva do jornalismo. Para a juíza Carla Rister, sem a necessidade de uma base cognitiva específica comprovada, a estrutura institucional garantidora de status jurídico diferenciado a uma ocupação perde o sentido. Para o juiz Manoel Álvares, a interpretação é semelhante, no entanto, para ele, o jornalismo possui uma base cognitiva específica, o que justificaria uma regulamentação diferenciada.

Coube ao STF o voto final sobre a questão. No Recurso Extraordinário n. 511.961 do STF, tendo como relator o ministro Gilmar Mendes, encontramos discussão semelhante. Começando com um resumo da discussão do problema, descrevendo claramente os pontos favoráveis e contrários à recepção do artigo $4^{\circ}$, inciso V, do Decreto-Lei n. 972/1969, o ministro desenvolve sua argumentação, que é contrária à obrigatoriedade.

Para o ministro, a CF/1988 não recepciona o artigo $4^{\circ}$, inciso V, do Decreto-Lei n. 972/1969, pois este, em seu entendimento, fere o princípio de liberdade de expressão. A CF/1988 garante direitos individuais e inalienáveis, e a discussão acerca da Reserva Legal Qualificada - concedida quando o exercício de determinada ocupação pode causar danos a terceiros - deve levar em consideração a manutenção desses direitos. Está em jogo, portanto, uma discussão sobre a relação entre direitos individuais e coletivos.

Para o ministro Gilmar Mendes, o jornalismo é

uma profissão diferenciada por sua estreita vinculação ao exercício das liberdades de expressão e informa- ção. O jornalismo é a própria manifestação e difusão do pensamento e da informação de forma contínua, profissional e remunerada. Os jornalistas são aquelas pessoas que se dedicam profissionalmente ao exercício pleno da liberdade de expressão. O jornalismo e a liberdade de expressão, portanto, são atividades que estão imbricadas por sua própria natureza e não podem ser pensadas e tratadas de forma separada. (RE: fl. 46-47)

Interessante notar o entendimento do Ministro a respeito do termo 'profissão'. Para ele, e para a corte em geral, que seguiu seu voto, a profissão não necessariamente está ligada a um aparato institucional garantidor de um status diferenciado em relação a outras ocupações, mas sim a um comportamento profissional no desempenho das atividades no trabalho. "O jornalismo é a própria manifestação e difusão do pensamento e da informação de forma contínua, "profissional', e remunerada". O 'profissional' aqui surge como termo que indica comportamento, na frase seguinte "Os jornalistas são aquelas pessoas que se dedicam 'profissionalmente' ao exercício pleno da liberdade de expressão", o termo 'profissionalmente' também indica uma forma de comportamento.

A problemática recai então no grau de liberdade desse exercício profissional. Para o STF,

as restrições legais à liberdade de exercício profissional somente podem ser levadas a efeito no tocante às qualificações profissionais. A restrição legal desproporcional e que viola o conteúdo essencial da liberdade deve ser declarada inconstitucional. (RE: fl. 38)

O artigo $4^{\circ}$, inciso V, do Decreto-Lei n. 972/1969 é considerado pela corte como restrição legal desproporcional, que viola o princípio de liberdade de expressão e de profissão no caso do jornalismo. A ordem constitucional, na compreensão da corte, somente admite algum tipo de regulamentação se esta reforçar e proteger o exercício profissional da liberdade de expressão e informação. Fora desse enquadramento, qualquer lei seria inconstitucional.

Tal entendimento não significa, para a Corte, liberdade total e irrestrita. Assim como a liberdade de profissão não é absoluta, a liberdade de expressão e informação também não, mas no caso do jornalismo a responsabilização civil e penal só poderá vir a posteriori. O diploma como credencial - e todo o processo de formação e socialização profissional que ele implica - não seria uma medida eficaz contra o exercício abusivo da profissão.

O diploma também não seria um instrumento capaz de proteger os direitos dos jornalistas das empresas de jornalismo. Na compreensão da corte, ele não fortaleceria os profissionais diante de possíveis abusos. A saída apresentada pela Corte é a autorregulação, 
que estaria em sintonia com a ordem constitucional e também com as liberdades de expressão e informação. Empresas de comunicação e jornalistas deveriam encontrar as melhores formas de estruturar suas relações, desde que obedecidos os princípios legais da regulamentação das relações de trabalho do país.

A interpretação do STF está em sintonia com a interpretação da Corte Interamericana de Direitos Humanos, que em 1985 já havia se pronunciado sobre a questão ao ser consultada pelo governo da Costa Rica sobre a exigência de diploma em Curso Superior em Jornalismo para exercer a profissão no país.

A Corte Interamericana de Direitos Humanos proferiu decisão no dia 13 de novembro de 1985, declarando que a obrigatoriedade do diploma universitário e da inscrição em ordem profissional para exercício da profissão de jornalista viola o art. 13 da Convenção Americana de Direitos Humanos, que protege a liberdade de expressão em sentido amplo. (RE: fl. 58)

Talvez o ponto mais importante na sentença seja o final do voto do relator, o ministro Gilmar Mendes, quando este procura mostrar a dimensão política do Decreto-Lei n. 972/1969. Vejamos

Está claro que a exigência de diploma de curso superior em jornalismo para o exercício da profissão tinha uma finalidade de simples entendimento: afastar dos meios de comunicação intelectuais, políticos e artistas que se opunham ao regime militar. Fica patente, assim, que o referido ato normativo atende a outros valores que não estão mais vigentes em nosso Estado Democrático de Direito. [...] este Decreto-Lei n. 972/1969 não passaria sob crivo do Congresso Nacional no contexto do atual Estado constitucional, em que são assegurados direitos e garantias fundamentais a todos os cidadãos. (RE: fl. 72)

O que Cardiani (2009) considera uma questão de diferenciação técnica, a Corte considera uma estratégia política. Somente o ministro Marco Aurélio votou contra o relator Gilmar Mendes, com o argumento de o que se encontrava em jogo eram quarenta anos de regulamentação que estavam sendo rejeitados. Regulamentação pela qual a sociedade teria se organizado para cumprir, de uma maneira ou de outra. Para o ministro Marco Aurélio, escolas de jornalismo foram criadas, pessoas investiram nessa formação, e a decisão do STF não estaria levando em conta essa realidade que se desenvolveu no país a partir da regulamentação. Ainda segundo ele, a exigência do diploma para o exercício profissional do jornalismo daria segurança jurídica maior aos consumidores de notícias. O ministro elenca as atividades específicas ao jornalista descritas no Decreto-Lei n. 972/1969 e argumenta que elas não seriam bem desempenhadas apenas com a prática, mas a formação em Ensino Superior seria necessária.

\section{IV}

Existem saberes e técnicas específicas relacionados à prática da divulgação de informação e expressão de opiniões através do sistema midiático, passíveis de regulamentação prévia em um regime democrático? Tal pergunta nos leva a problematizar a relação entre saberes e regulamentação profissional, como faz Johnson (1995).

Ao relatar as decisões judiciais tomadas em torno da obrigatoriedade do diploma em jornalismo para exercer a profissão, não pretendemos passar a imagem de que, no passado, o cumprimento desta determinação legal era efetivo. Como mostra Dines (2002), tanto por parte das empresas de comunicação, como por parte de estudantes, faculdades e mesmo em determinado período da própria Federação Nacional dos Jornalistas (FENAJ) - que atualmente lidera campanha pela obrigatoriedade do diploma -, não houve mobilização forte pela regulamentação da profissão com exigência de Nível Superior, nem fiscalização. A questão da obrigatoriedade de uma credencial foi simplesmente deixada de lado, sendo acionada politicamente, como mostram Abreu (2003) e Dines (2002), durante o regime militar.

Mostramos em trabalho anterior (Nascimento, 2008) a existência do registro precário dado a pessoas que exerciam o jornalismo sem diploma quando não havia cursos disponíveis na região. Mesmo assim, o jornalismo era pensado pelos jornalistas com base em um discurso de profissionalismo. Assim como Aldridge e Evetts (2003), para o caso britânico, e Fidalgo (2008), para o caso português, argumentamos então que a ocorrência de um discurso profissional não necessariamente se refletia num aparato institucional que organizasse o jornalismo como profissão legalmente diferenciada.

A definição dada pelo ministro Gilmar Mendes ao jornalismo reflete essa visão. Para ele, o jornalismo é o exercício profissional da liberdade de expressão, e o profissionalismo é visto como comportamento no mercado de trabalho e não como forma institucional de regulamentação do trabalho.

Consideramos que o profissionalismo ao qual se refere o Ministro Gilmar Mendes está mais próximo do modelo defendido por Evetts (2006). Esta autora entende profissionalismo como um discurso de controle, no sentido dado por Foucault, que tem sido amplamente utilizado por gerentes do trabalho em organizações públicas e privadas. Tem como características centrais a racionalidade-legal no processo de tomada de decisões, uma estrutura hierárquica de autoridade com a padronização das práticas de trabalho, um processo de revisão do desempenho e prestação de contas, mas também pode tomar contornos emancipatórios, sendo usado por diversos tipos de organizações como estratégia de fortalecimento da ação política. O com- 
portamento profissional aqui não está necessariamente ligado à existência de credenciais e à regulação via alguma associação colegial, um tipo de comportamento profissional derivado de instituições colegiadas do tipo profissional clássico como existente no Direito e Medicina.

$\mathrm{Na}$ decisão final do STF, o jornalismo aparece na intersecção entre liberdade de expressão/informação e liberdade de profissão, ambas garantias constitucionais, e tal posição a torna diferenciada em relação a outras ocupações do mundo do trabalho. No jornalismo, as liberdades de expressão/informação e liberdade de profissão estão sobrepostas. O discurso da não especificidade da base cognitiva do jornalismo ganha força quando a credencial antes exigida para o exercício legal da profissão é associada a um regime de exceção política, na medida em que o jornalismo é interpretado como o exercício profissional da liberdade de expressão/informação - característica de um regime democrático - a legitimidade de tal credencial é dissolvida. A relação entre técnica e ética/ethos profissional via credencialismo é vista como antidemocrática no jornalismo. Assim, o processo de profissionalização - tomando as disputas discursivas em torno das fronteiras da profissão - toma contornos muito mais políticos que técnicos.

\section{Referências}

ABREU, Alzira. Jornalistas e jornalismo econômico na transição democrática. In: ABREU, Alzira Alves de. LATTMAN-WELTMAN, Fernando, KORNIS, Mônica Almeida. Mídia e política no Brasil: jornalismo e ficção. Rio de Janeiro: Ed. da FGV, 2003. P. 13-74.

ALDRIDGE, Meryl; EVETTS, Julia. Rethinking the conception of professionalism: the case of journalism. British Journal of Sociology, v. 54, n. 4, dec, p. 547-564, 2003.

ÁLVARES, Manoel. A conquista histórica no TRF $-3^{\mathrm{a}}$ Região. In: FENAJ: Federação Nacional dos Jornalistas (Org.). Formação Superior em Jornalismo: uma exigência que interessa à sociedade. Florianópolis: Ed. da Fenaj, 2008.

BARBOSA, Marialva. História cultural da imprensa: Brasil, 1900-2000. Rio de Janeiro: Mauad X, 2007.

CANDINI, Heci Regina Journalists and intellectuals in the origins of the Brazilian press (1808-22). Journalism, v. 10, n. 1, p. 29-44, 2009.

COELHO, Edmundo Campos. As profissões imperiais. Rio de Janeiro: Record, 1999.

DINES, Alberto. A questão não é do diploma, mas do canudo. In: FENAJ: Federação Nacional dos Jornalistas (Org.). Formação Superior em Jornalismo: uma exigência que interessa à sociedade. Florianópolis: Ed. da Fenaj, 2002.

DINIZ, Marli. Os donos do saber: profissões e monopólios profissionais. Rio de Janeiro: Revan, 2001.

EVETTS, Julia. Short Note: The Sociology of Professional Groups. Current Sociology, v. 54, n. 1. p. 133-143, 2006.

FIDALGO, Joaquim. Journalists' professional identity: new challenges to na old quest. In: 5TH INTERIM CONFERENCE OF THE INTERNATIONAL SOCIOLOGICAL ASSOCIATION. Challenges to professionalism: limitas and benefits of the Professional model, Research Committee 52, Sociology of Professional Groups, Oslo University College. Norway, 2008.

FOUCAULT, Michel. A verdade e as formas jurídicas. Rio de Janeiro: Nau, 2002.

FREIDSON, Eliot. Para uma análise comparada das profissões: a institucionalização do discurso e do conhecimento formais. Revista Brasileira de Ciências Sociais. São Paulo, ano 11, n. 31, jun. 1996.

FREIDSON, Eliot. Professionalism: the third logic. Cambridge: Polity Press, 2001.

JOHNSON, Terry. Governamentality and the institutionalization of expertise. In: JOHNSON, Terry; LARKIN, Gerry; SAKS, Mike (Orgs.). Health professions and the state in Europe. London: Routledge, 1995. p. 4-13.

MENDES, Ricardo Fontes. As disputas no campo profissional do jornalismo. Dissertação (Mestrado) - UFSCar, São Carlos, 1997. NASCIMENTO, Lerisson Christian. Profissionalização do jornalismo em Mossoró/RN: profissionalismo e poder local. Dissertação (Mestrado em Ciências Sociais)-UFSCar, São Carlos, 2008.

NEVES, Ricardo José. Vade Mecum da Comunicação Social. São Paulo: Ridel, 2000.

PÉCAULT, Daniel. Os intelectuais e a política no Brasil: entre o povo e a nação. São Paulo: Ática, 1990.

PENA, Felipe. Teoria do jornalismo. São Paulo: Contexto, 2005.

RISTER, Carla A. Processo n. 2001.61.00.025946-3 - $16^{\mathrm{a}}$ Vara Cível Federal/São Paulo. Disponível em: <http:// www.conjur.com.br/2003-jan-10/nao_preciso_diploma_ jornalista_brasil>. Acesso em: jul. 2011.

ROCHA, Paula Melani. A profissionalização num jornal popular: a concepção da noticia e a representação social sobre os leitores no Noticias Populares. Dissertação (Mestrado) - UFSCar, São Carlos, 1997.

RODRIGUES, Maria de Lurdes. Sociologia das profissões. Portugal: Celta, 2002.

SODRE, Nelson Werneck. História da imprensa no Brasil. 2. ed. Rio de Janeiro: Graal, 1977.

STF: Supremo Tribunal Federal. Recurso Extraordinário n. 511.961 de 2009. Disponível em: <http://www.stf.jus. br>. Acesso em: jul. 2011.

ZANETTI JÚNIOR, Hermes. Direitos coletivos lato sensu: a definição conceitual dos direitos difusos, dos direitos coletivos stricto sensu e dos direitos individuais homogêneos. In: AMARAL, Guilherme; CARPENA, Márcia Louzada Carpena (Coord.). Visões críticas do Processo Civil. Porto Alegre: Livraria do Advogado, 2005. 


\title{
A diploma in dispute: the requirement of the diploma of journalism in Brazil
}

\begin{abstract}
What is proposed in this paper is to demonstrate how the profession of journalism in Brazil have been subjected to litigations in the last years in Brazilian judiciary, particularly in the Federal Supreme Court - FSC. We show that the dispute has occurred around the obligatoriness of a college degree in journalism for the lawful professional practice. For the 1988 Brazilian Constitution some occupations have a qualified legal reserve, what means that they demand a college degree to the professional practice. The FSC has considered that journalism is an occupation in which the freedom of speech and the freedom of profession have the same nature. Based on the idea that in a democratic country there should not be any pre-regulation for the freedom of speech, the FSC has decided that there should not exist any kind of state regulation in the profession of journalism.
\end{abstract}

Keywords: profession; journalism; Supreme Court; expertise.

\section{Un título en disputa: el requerimiento del diploma en periodismo en Brasil}

\begin{abstract}
Resumen
El propósito de este trabajo es demostrar cómo la profesión de periodismo en Brasil ha sido objeto de controversias en los últimos años en los tribunales brasileños, particularmente, en la Corte Suprema - Supremo Tribunal Federal - STF. Se demuestra que el conflicto se produjo en torno al requerimiento del diploma en periodismo para el ejercicio legal de la profesión. Para la Constitución brasileña de 1988, algunas ocupaciones han caído una reserva legal cualificada, lo que significa que requieren un título universitario para la profesión. El STF considera el periodismo una profesión en la que la libertad de expresión y la libertad de ocupación tienen la misma naturaleza. Basado en la idea de que en un país democrático no debe haber regulación previa de la libertad de expresión, el STF decidió que no debería haber ningún tipo de regulación estatal en la profesión de periodista.
\end{abstract}

Palabras clave: profesión; periodismo; Supremo Tribunal-STF; peritaje.

Data de recebimento do artigo: 20-12-2010

Data de aprovação do artigo: 15-02-2011 